\title{
A success story
}

\section{Christel Möller and Christian Schönenberger highlight the benefits of studying a bachelor's degree in}

\author{
nanoscience at the University of Basel.
}

n 2001, the University of Basel was chosen

as the leading house for a national research

programme in nanoscience funded by the Swiss National Science Foundation. The establishment of this National Center of Competence in Research (now the Swiss Nanoscience Institute; SNI) gave birth to an interdisciplinary education programme in nanoscience.

At that time, most nanoscience teaching programmes were designed as master's programmes that would follow an existing disciplinary bachelor's programme in, for example, physics, chemistry or biology. Hence, typically, a student would first specialize in one discipline, for example physics, and then subsequently move into the broader interdisciplinary field of nanoscience. We at the University of Basel felt strongly that this was the wrong approach and that in nanoscience one should initially study a curriculum as wide as possible and then specialize later. We decided to develop a nanoscience study programme in which the core disciplines of physics, chemistry, biology and mathematics have similar weights and are studied in parallel from the start - a similar approach was taken by the University of Aarhus in Denmark. Our bachelor's degree in nanoscience was launched in 2002, and now nearly 15 years since the first students registered for it, we are convinced that the approach has paid off and that we have developed a sustainable curriculum. Having completed their master's degrees, the nanoscience students leave university as well-trained young scientists who - as well as having considerable know-how - have learnt how to work in interdisciplinary teams and think in a joined-up way.

The bachelor's programme in nanoscience at the University of Basel has an intake of about 40 students per year. It primarily attracts students who have left school with a wide interest in sciences, but who are not yet certain about which topic to specialize in. Studying physics, chemistry and biology together is very demanding, but also highly rewarding. Elise Aebi, who has just completed her master's degree, sums up this aspect of the course: "Nano students are a small group. We all know each other. We know the programme is difficult, so we work together and not against each other" (go.nature.com/2bXBOs4).

The nanoscience study programme rests on three key pillars: interdisciplinarity, practice-oriented training and maximum freedom of choice and flexibility.

Interdisciplinary knowledge is essential to tackling questions in nanotechnology. Nanoscience students in Basel receive this broad-based training mainly as part of their bachelor's programme. They also get to experience interdisciplinarity in eight short internships that they complete in different research groups during the fifth and sixth semesters. These research internships provide practice-oriented training and are often singled out by our students as being particularly motivating and inspirational. The students spend between one and three weeks embedded in ongoing research projects of different working groups at the University of Basel, neighbouring universities and research institutions. Currently, around 30 topics are available, from which each student chooses eight. Through these courses, they learn early on how to work independently in the laboratory and handle small research projects, including how to write up and present scientific work. Aebi recalls: "The most amazing part of the bachelor's programme was the block courses, where you are involved in lab work in one of the research teams. You work like a real researcher and can make a contribution. We are allowed to work with complicated machines. We are given that responsibility and trusted to succeed" (go.nature.com/2bXBOs4).

Alongside the lectures in physics, chemistry and biology, the curriculum includes nano-specific courses and events. For example, trips to industrial companies and research institutions give the students an opportunity to see nanotechnology being applied in concrete ways. Some of our graduates end up being employed by the companies they visited at the start of their course. The SNI also has a grant programme that supports applied research in collaboration with industrial companies. This provides ongoing opportunities for project work or master's theses on applied research topics.

Students have a large choice of master's programmes after the successful completion of a bachelor's degree in nanosciences. The students can register for a master's programme in physics, chemistry, biology or nanoscience without requiring any additional credit points. If they stay in nanoscience, the emphasis will be on practical lab work. In addition, to be able to select their own courses and classes from a wide range of options, students complete two pieces of project work and a master's thesis in at least two different disciplines, which the students can choose themselves. We also encourage our students to do one of their projects abroad. For example, Andreas Reichmuth wrote his master's thesis on nanoparticles in immunotherapy at the Massachusetts Institute of Technology, USA. He says "It was fantastic to learn that I was able to cope well, even when studying at such a renowned institute."

We do not have precise figures about the types of career that graduates from the bachelor's programme in nanoscience undertake yet. Most of them move on to a $\mathrm{PhD}$ programme. From personal experience in the SNI PhD school and feedback from colleagues, we know that former nanoscience students are suitable for a wide range of job profiles, can work independently and reliably, and are good team players. After finishing their doctorate, some young scientists remain in academia, while others switch to industry or - like Markus Mangold, the founder of IRsweep - set up their own company. As Mangold explains "As a nanoscience student, I enjoyed a broad basic education in natural sciences with a specialization during the Master's program. Now, as a founder of IRsweep, the scope of my basic studies helps me to understand the biological and chemical processes of my future customers in industry. Thanks to the specialization, I am able to develop high-end sensors to monitor these processes" (K. Winkelmann and B. Bhushan (eds) Global Perspectives of Nanoscience and Engineering Education; Springer, 2016).

\section{CHRISTEL MÖLLER and CHRISTIAN} SCHÖNENBERGER are at the Swiss Nanoscience Institute, University of Basel, Klingelbergstrasse 82, CH-4056 Basel, Switzerland.

e-mail:c.moeller@unibas.ch; christian.schoenenberger@unibas.ch 